\title{
Correction to: Right infraaxillary thoracotomy approach for upper thoracic vertebral decompression and fusion at T2-T6 levels: a technical note
}

\author{
Jia Liu ${ }^{1} \cdot$ Shengfa $\mathrm{Li}^{2} \cdot \mathrm{Ke} \mathrm{Huang}^{1} \cdot \mathrm{Xianzhe} \mathrm{Lu}^{1} \cdot \mathrm{Yu} \mathrm{Shi}^{1} \cdot \mathrm{Kegong} \mathrm{Xie}^{1} \cdot$ Yujing Tang $^{1}$ (1)
}

Published online: 24 August 2018

๑) Springer-Verlag GmbH Germany, part of Springer Nature 2018

\section{Correction to: European Spine Journal https://doi.org/10.1007/s00586-018-5686-x}

Unfortunately, the HTML version of this article was published with incorrect copyright line.

It has been corrected now.

The original article can be found online at https://doi.org/10.1007/ s00586-018-5686-x.

\section{Kegong Xie}

13707766465@163.com

$\triangle$ Yujing Tang

tangyujin196709@163.com

1 Department of Orthopaedics, Affiliated Hospital of Youjiang Medical University for Nationalities, No. 98 Urban and Rural Road, Baise 533000, Guangxi, People's Republic of China

2 Department of Orthopaedics, Huizhou First

People's Hospital, Huizhou 516001, Guangdong,

People's Republic of China 